\title{
Crónica de una efusión: Alfonso Reyes, Luisa Luisi y el Comité Uruguay-México
}

\author{
Mariana Moraes Medina* \\ Recibido el 11 de octubre de 2018; aceptado el 22 de noviembre de 2018
}

\section{RESUMEN}

Este artículo estudia la relación de Alfonso Reyes con Luisa Luisi y el Comité Uruguay-México a partir del análisis del diario del autor y la correspondencia —inédita— mantenida con la escritora uruguaya, así como de los encuentros, discursos y colaboraciones publicadas en revistas y diarios de la época. El desembarco oficial de Reyes en Uruguay, en mayo de 1928, formó parte, al tiempo que operó como un catalizador, de una "ola de difusión de los valores” del México posrevolucionario. La reconstrucción de la relación intelectual entre Reyes y la escritora uruguaya, así como la reflexión sobre las dinámicas de colaboración y conflicto entre ambos proponen nuevas claves para la crítica biográfica de los autores y los estudios sobre la diplomacia cultural de México en América del Sur.

Palabras clave: Alfonso Reyes; Luisa Luisi; correspondencia; Comité UruguayMéxico; diplomacia cultural.

* Investigadora SNI-ANII de Uruguay. Becaria del Programa de Becas Posdoctorales de la UNAM, Centro de Investigaciones sobre América Latina y el Caribe (CIALC), asesorada por la doctora Regina Crespo Franzoni, correo electrónico: mmoraes.medina@gmail.com. Orcid: 0003-2826-5580. 


\section{Chronicle of an effusion: Alfonso Reyes, Luisa Luisi and the Uruguay-Mexico Committee}

\section{AbStraCT}

This article studies the relationship among Alfonso Reyes, Luisa Luisi and the Uruguay-Mexico Committee. It is based on the analysis of Reyes' diary and the unpublished correspondence he maintained with the Uruguayan writer Luisa Luisi, as well as on encounters, speeches and collaborations published in magazines and newspapers of the time. Reyes' official arrival in Uruguay, in May of 1928, was part of and also catalyzed a "wave that diffused the values" of post-revolutionary Mexico. Reconstructing the intellectual relationship between Reyes and Luisi, as well as reflecting on the collaboration and conflict dynamics between the two, lends new insights into biographical criticism of the authors and studies on Mexico's cultural diplomacy in South America.

Key words: Alfonso Reyes; Luisa Luisi; correspondence; Uruguay-Mexico Committee; cultural diplomacy.

\section{REYES Y URUGUAY, UNA DEUDA PENDIENTE}

T a conjugación de los oficios de escritor y diplomático hizo de Alfonso $ـ$ Reyes (1889-1959) una de las figuras más destacadas del ámbito hispanoamericano de entreguerras. Provisto de un notable carisma para la sociabilidad intelectual y de un gran prestigio, el escritor alimentó un sinfín de intercambios culturales entre el norte y el sur de América Latina, colaboró con el fortalecimiento de una conciencia continental ${ }^{1}$ y especialmente con la política de defensa y proyección internacional de la Revolución mexicana. ${ }^{2}$ Este marco de acción tuvo vigencia desde el gobierno de Venustiano Carranza hasta la década de los treinta, años en los que México invirtió un gran esfuerzo en su propaganda en Sudamérica con la finalidad de promover la imagen de un gobierno constitucional - acuciado como estaba por la prensa norteamericana y su difusión de la barbarie del proceso revolucionario- - y

1 Véase Granados, “Alfonso Reyes en Sur América: diplomacia y campo intelectual en América Latina, 1927-1939”.

2 La trayectoria diplomática de Alfonso Reyes se extendió desde 1913 a 1946 (con un interregno durante 1914-1920). El inicio de su carrera en el servicio exterior mexicano tuvo lugar tras la muerte de su padre, el general porfirista Bernardo Reyes, quien participaba del golpe militar contra Madero. Este origen reaccionario de Reyes lo acompañaría siempre y constituiría una suerte de paradoja en quien se convirtió en uno de los más brillantes representantes del México posrevolucionario. 
afianzar lazos políticos y comerciales con aquella zona del continente. Como ha estudiado Yankelevich, ${ }^{3}$ la difusión de los valores y la creación de empatía hacia la obra de la Revolución en los sudamericanos estuvieron en manos de los movimientos de estudiantes universitarios y de las representaciones obreras e intelectuales. Para los primeros y los segundos, los gobiernos posrevolucionarios fomentaron el desplazamiento y los encuentros entre líderes universitarios y obreros -mexicanos y extranjeros- y crearon agregadurías en todas sus legaciones. Para los terceros, promovieron la colocación de renombrados escritores mexicanos en representaciones diplomáticas o el encargo de misiones puntuales en el exterior.

Es así como, en 1927, Alfonso Reyes llegaría a Buenos Aires portando las credenciales de embajador de México. Tenía entonces 38 años y una trayectoria europea que lo ungía como un escritor consagrado, aspecto que favoreció su incorporación a las redes sudamericanas, que vieron en él, aparte de un diplomático en el servicio de México, a un eximio intelectual. Pero lo cierto es que la coyuntura mexicana no le deparaba una tarea fácil en el Río de la Plata, en especial por los efectos de la política anticlerical del presidente Calles. La promulgación de la ley que determinaba la separación de Estado e Iglesia en 1926 había desatado la Guerra cristera y colocaba a la representación mexicana en el exterior en la mira de la prensa y los movimientos católicos. ${ }^{4}$ También habría que considerar el peso, para el desempeño de la labor diplomática en Buenos Aires, de los asuntos derivados del conflicto por el petróleo y otros intereses económicos de Estados Unidos, fuerte aliado comercial y político de las naciones sudamericanas.

Con todo, Reyes mostró gran eficacia a la hora de contrarrestar el desprestigio que se cernía sobre la imagen de México. "Se dedicó a difundir los logros del proceso posrevolucionario mexicano, especialmente en los ámbitos de la educación y la cultura” 5 y transformó a la Embajada de México en Buenos Aires en un centro de gran efervescencia cultural no sólo para el país, sino también para la región, pues su labor resonó también en el campo intelectual uruguayo, un asunto que no ha recibido hasta el momento suficiente atención crítica. ${ }^{6}$ Atendiendo a esto, el objetivo del presente trabajo es avanzar en la indagación acerca de los efectos de la residencia argentina de

3 Cfr. Yankelevich, Miradas australes: propaganda, cabildeo y proyección de la revolución mexicana en el Río de la Plata, 1910-1930, 1997.

4 Garciadiego, "Alfonso Reyes en la Argentina: desencuentros diplomáticos y amistades literarias”, p. 235.

5 Ibíd., p. 237.

6 Suele recordarse, al pensar en Reyes y Uruguay, el vínculo del autor con Juana de Ibarbourou, relación de la que queda un testimonio formidable en su correspondencia, editada en 2001 por Serge Zaïtzeff: Reyes/Ibarbourou, Grito de auxilio. Correspondencia. 
Alfonso Reyes sobre la orilla oriental del Plata, a través del estudio de su vínculo con la escritora uruguaya Luisa Luisi (1883-1940), la entusiasta artífice, a través del Comité Uruguay-México, del desembarco efectivo de Reyes en Montevideo en 1928. ${ }^{7}$

Esta relación sólo ha merecido hasta ahora algunos comentarios incidentales o de corte anecdótico por parte de la crítica alfonsina (los estudios sobre Luisi sencillamente no registran esta relación), con base en los encuentros e intercambios registrados por el propio autor en su diario. Nuestro trabajo, si bien retoma esta fuente, se basa especialmente en la correspondencia inédita de los escritores, conservada en el archivo particular de Alfonso Reyes (Capilla Alfonsina/INBA). Se trata de un corpus de un total de 85 folios (entre cartas manuscritas, tarjetas de visita e impresos), enviados entre julio de 1927 y agosto de 1933, y que abren un rico campo de exploración, ${ }^{8}$ pues permiten reconstruir la historia de un breve, pero intenso fervor por lo mexicano en Uruguay, profundizar en la interacción del autor de $V i$ sión de Anáhuac con la intelectualidad del país, la naturaleza y el contexto de sus intercambios y las percepciones culturales vigentes en el momento. Por otra parte, la doble naturaleza de esa relación Luisi-Reyes, atravesada por la colaboración y el conflicto, ilumina ciertas claves de la compleja construcción de Reyes como literato y diplomático al servicio de México en el exterior.

\section{LUISA LUISI Y EL COMITÉ URUGUAY-MÉXICO}

En Uruguay el apellido Luisi resuena como aquél que identifica a un conjunto de mujeres que lograron conquistar un buen número de espacios y derechos a principios del siglo xx. Hijas de inmigrantes europeos de ideas masónico-liberales, las hermanas Luisi formaron parte del primer grupo de mujeres egresadas de la universidad y tuvieron un destacado papel en el ámbito público. ${ }^{9}$ En el caso de Luisa, maestra de formación y de ejercicio, su

7 La primera vez que Alfonso Reyes puso pie en Montevideo fue, en realidad, en una escala del viaje entre Río de Janeiro y Buenos Aires, destino en el que tomaría posesión del cargo de Embajador de México, el 30 de junio de 1927. Consignó en su diario esa visita como "un instante” en la ciudad en el que se entrevistó con los diplomáticos mexicanos residentes en el país para luego retomar su viaje hacia Buenos Aires (Reyes, Diario II. París, 19 de marzo de 1927- Buenos Aires, 4 de abril de 1930, p. 31).

8 En ese conjunto, la mayoría son cartas de Luisi; se identifican solamente dos cartas mecanografiadas escritas por Reyes. Salvo estos casos puntuales, las cartas que el autor envió a la escritora no se conservan.

9 Paulina Luisi fue la primera Doctora en Medicina y Cirugía del Uruguay (1909) y reconocida activista del feminismo (su lucha por los derechos de la mujer tuvo como principal conquista el voto femenino). Clotilde Luisi, por su parte, la primera Doctora en Derecho del 
labor recorrió los campos de la literatura, el periodismo y la pedagogía. Formó parte de una generación de "maestras poetas que florecieron en América", ${ }^{10}$ entre las que destacaron Gabriela Mistral y Alfonsina Storni. Su obra literaria se enmarca en el posmodernismo y conforma cuatro poemarios: Sentir (1916), Inquietud (1921), Poemas de la inmovilidad, Canciones al sol (1926) y Polvo de días (1935). A esto hay que añadir sus trabajos como crítica literaria, la mayoría recogidos en A través de libros y autores (1925) y La literatura del Uruguay en su Centenario (1930), y otros tantos dispersos en publicaciones de la época. ${ }^{11}$ A pesar de que lidió desde joven con las secuelas de una parálisis, Luisi mostró un enorme dinamismo cultural y político. Militó en el Partido Colorado, grupo que a través del batllismo había extendido su hegemonía sobre el campo intelectual. ${ }^{12}$ Como a otros tantos escritores uruguayos del periodo (entre ellos, Oribe, Sabat Ercasty, Zum Felde), la cercanía con el poder le deparó a la poeta cierta protección por parte del Estado, siendo durante varios periodos miembro del Consejo Nacional de Enseñanza Primaria y Normal.

país (1911), catedrática de la misma facultad y directora de la Universidad de Mujeres. De las restantes hermanas, Inés también fue médica, mientras que Ana y Elena, maestras, al igual que Luisa.

10 Santacreu, “Luisa Luisi: sentada y muda al borde de la vida”, p. 131.

11 Este pasaje de Ida Vitale lo desarrolla con gran elocuencia: "Extraño es el caso de Luisa Luisi, que continuó la poesía filosófica y poco sensual de María Eugenia Vaz Ferreira y después de alcanzar prestigio y consideración, fue siendo olvidada por la crítica. Olvido injusto porque, crítica ella misma, lo fue muchas veces atinada y precisa. Como poeta, logró comunicar la angustia de sentirse marginada de la vida por la enfermedad que la atacó en sus últimos años, haciendo correr, por una poesía inicialmente muy conceptual, una controlada emotividad" (Vitale, Los poetas del Veinte, p. 331). Prueba de ese olvido es la escasez de trabajos sobre su obra y trayectoria intelectual; al respecto, pueden consultarse: Benítez, Luisa Luisi. El ensueño dolorido ,1981; Álvarez, Introducción a Luisi, Luisa, Antología: verso y prosa, 1998; Murciano, Hacia una revisión de la poesía posmodernista femenina en el Uruguay (en su primera época), 2002; Santacreu, "Luisa Luisi: sentada y muda al borde de la vida”, 2001, y López, El legado de las hermanas Luisi, cien años después, 2013.

12 El Partido Colorado - uno de los dos partidos tradicionales uruguayos, junto al Blancotuvo el batllismo su desarrollo ideológico más decisivo para la historia política del país. Partiendo de la tradición liberal, José Batlle y Ordóñez (1856-1929) le imprimió a sus presidencias (1903-1907; 1911-1915) una dirección progresista, republicana y reformista. Los logros sociales (defensa del derecho a huelga, la jornada laboral de ocho horas, la extensión de la educación, la creación de un sistema de jubilaciones y pensiones o la ley de divorcio), la promoción de una moral laica y la efectividad económica de sus gobiernos hicieron que Uruguay destacara en el concierto latinoamericano. Hay que mencionar además que el batllismo consolidó un imaginario social nacional en torno a los siguientes puntos fuertes: el legalismo, la primacía de lo público sobre lo privado, de lo urbano sobre lo rural, la idea de una sociedad pluralista, de clases medias e integrada, un gran optimismo en relación a la convivencia, el laicismo y la raíz europea de la población. Todo lo cual ayudó a forjar la tan difundida imagen de Uruguay como "Suiza de América”. Cfr. Caetano, Los uruguayos del Centenario. Nación, ciudadanía, religión y educación (1910-1930) y La República Batllista. 
Un aspecto desatendido por los biógrafos de Luisi interesa especialmente a este trabajo: el de su intenso americanismo, una orientación que fue más allá de sus lecturas, trabajos críticos y amistades (que incluían a Gabriela Mistral, Luis Alberto Sánchez, Ventura García Calderón y Enrique González Martínez, entre otros). La influencia del pensamiento de Rodó, la adhesión a los fundamentos de la reforma universitaria y la cercanía con posiciones de izquierda, fueron decisivos para que Luisi diera firmes pasos hacia un activismo antiimperialista y comprometido con la construcción de una conciencia continental tanto a través de la pluma como de la acción. Desde estas afinidades debe comprenderse su liderazgo en la fundación del Comité Uruguay-México, ${ }^{13}$ empeño en el que fue secundada por un grupo de alrededor de cuarenta intelectuales.

La conformación del organismo tuvo a la propia Luisi en la presidencia, mientras que Carlos Quijano ${ }^{14}$ e Ildefonso Pereda Valdés se desempeñaron como secretarios. Entre sus miembros figuraban además: Fernán Silva Valdés, Clotilde Luisi, Oscar Cosco Montaldo, Adolfo Montiel Ballesteros, Emilio Frugoni, Alberto Zum Felde, Orestes Baroffio, Mercedes Pinto y Carlos Sabat Ercasty. ${ }^{15}$

La idea, concebida entre finales de 1927 y principios de 1928, debe enmarcarse en una corriente internacional de apoyo al gobierno del presidente Calles, quien era acuciado periódicamente por las amenazas de invasión de Estados Unidos y de continuo por los ataques de la prensa norteamericana.

${ }^{13}$ El Comité Uruguay-México no ha recibido hasta ahora atención crítica, más allá de menciones puntuales acerca de su existencia en: Caetano y Rilla, El joven Quijano, 1900-1933: izquierda nacional y conciencia crítica, p. 63; Caetano, La República Batllista, p. 274; y un breve comentario del accionar del grupo, aunque con varias imprecisiones, en Rama, "La Revolución mexicana en Uruguay”, pp. 182-184.

${ }^{14}$ La presencia del futuro fundador de la revista Marcha, Carlos Qujiano (1900-1984) en el Comité es muy significativa. En su residencia como estudiante en París, entre 1924-1927, se integró a la red americanista que por aquel entonces nucleaba a figuras como Juan J. Arévalo, Asturias, Toño Salazar, y los mexicanos Vasconcelos, Siqueiros y Pellicer, como miembro del Comité de Solidaridad Latinoamericana, participó de la organización de un acto de apoyo a México en el que participaron Unamuno, Ingenieros, Ugarte y Haya de la Torre, entre otros. En 1925, fue invitado por el gobierno de Calles a visitar México, como secretario de José Ingenieros. Parte de la gestión de este viaje corrió por cuenta de Reyes, en ese momento, Embajador de México en París.

${ }^{15}$ Resulta oportuno señalar que los intelectuales que manifestaron su admiración por México a fines de la década de los veinte abrevaban del liberalismo progresista y mostraron una marcada simpatía por el socialismo. Sin ir más lejos, la propia Luisi definió a su grupo político (“Avanzar") como el ala socialista del Partido Colorado. En lo cultural, si bien se reconoce en el momento una fuerte vocación americanista, la intelectualidad uruguaya de las primeras décadas del xx había sido educada en moldes europeístas (afrancesados) y estaba fuertemente adherida aún al simbolismo y al modernismo. Las muestras de vanguardia nacional eran escasas. 
La relación entre los dos países había vuelto a entrar en tensión a partir de las medidas proteccionistas impuestas por el gobierno mexicano, en especial las que restringían la extracción del petróleo por parte de extranjeros. A esto se sumó el encono por el apoyo mexicano a Sandino cuando la intervención estadounidense en Nicaragua y por el acercamiento diplomático entre México y la Unión Soviética. Pero fue en la difusión de la crisis interna derivada del conflicto religioso que Estados Unidos encontró un flanco débil en la nación vecina; supo sacar provecho de la Guerra cristera como una muestra de la inestabilidad e incapacidad de México de asentar las bases constitucionales de la Revolución iniciada en 1910.

Entre la intelectualidad progresista del Uruguay, el presidente Calles gozaba de gran reconocimiento en virtud de sus políticas laicistas, su cercanía con el movimiento obrero y su esfuerzo por suprimir en el país, a través de instituciones y de leyes, la necesidad de caudillos. En cierto modo, los intelectuales vieron en este gobierno un avance hacia la "fase constructiva" de la Revolución, a la que el propio Calles había aludido en su toma de posesión. ${ }^{16}$ Por otra parte, el celo con el que presidente promovía la extensión de la educación, unido a su condición de maestro, dotaban al gobierno de un halo de humanismo. En cierto modo, las políticas económicas y sociales implementadas por Calles tenían numerosos puntos de contacto con el batllismo, lo que permite afirmar que un elemento importante para la afinidad y solidaridad con el México posrevolucionario radicó en la voluntad reformista que los intelectuales reconocieron en su programa. ${ }^{17}$

En lo que hace a los propósitos del Comité, éste declaró perseguir una "obra de acercamiento americano" para la que proponía un "programa de acción constructiva por el conocimiento verdadero de ambos países”. Fue de esta manera que un sector de la intelectualidad uruguaya manifestaría su

16 Krauze, Plutarco Elías Calles. Reformar desde el origen, p. 49.

17 Gerardo Caetano objetó esta idea alegando que el reformismo mexicano y el uruguayo responden a un origen ideológico y cultural diferente (La República Batllista, p. 274). Si bien reconocemos cierta validez en su argumento, en las declaraciones de los miembros del Comité se advierte un gran interés por las reformas nacidas de la Revolución y la valoración de éstas como una obra propia de países de avanzada. En efecto, como ha señalado Rama, durante mucho tiempo los dos países encabezaron la vanguardia latinoamericana en cuestiones de reformas y, en el caso de Uruguay, la prensa y otras publicaciones revelan un gran interés por la Constitución mexicana de 1917 ("La Revolución mexicana en Uruguay”, p. 179). Sin embargo, el fervor por México en el campo intelectual uruguayo de 1928 — eminentemente batllista — no deja de ser llamativo y paradojal si se atiende, por un lado, a la tradición de "país de espaldas a América" que se fortalecía por esos años en el "culto a la excepcionalidad uruguaya en el concierto internacional y fundamentalmente dentro de América Latina" (Caetano, Los uruguayos del Centenario, p. 10) y por otro, por la condena de la Revolución que llevó adelante el batllismo, gran aliado de los capitales anglonorteamericanos y de la doctrina del panamericanismo (Caetano, La República Batllista, pp. 270-77). 
solidaridad moral y espiritual "a la gran obra de construcción democrática que se gesta, dolorosa y acaso turbiamente en este gran país hermano". ${ }^{18}$ Atendiendo a ello, durante los meses de mayo a noviembre de 1928, el organismo llevó adelante un ciclo de conferencias sobre literatura, arquitectura, historia, música, política y cultura de México, en espacios como el Paraninfo de la Universidad de la República y principalmente en la Casa del Arte. Anuncios y reseñas de estas actividades, así como las convocatorias a reuniones y el manifiesto del organismo, fueron difundidos a través de los periódicos El Día y El País, y la revista literaria La Pluma. ${ }^{19}$

Como acto inaugural, el Comité decidió organizar un homenaje a México en la figura de su embajador en Buenos Aires, el reconocido escritor Alfonso Reyes.

\section{REYES Y EL HOMENAJE A MÉXICO}

Las gestiones de Luisi para atraer a Reyes a Montevideo comenzaron en el mes de enero de 1928, cuando se entrevistó con el mexicano en Buenos Aires. ${ }^{20}$ En esa oportunidad, la autora le extendió una invitación para dictar una conferencia sobre nueva literatura mexicana en un evento organizado por el Comité Uruguay-México previsto para el mes de abril de ese año. Transcurrido un tiempo, el pedido de una conferencia se transformó en un acto de homenaje y fue pospuesto al mes de mayo. Si se observa la correspondencia de los autores, la primera y extensa carta de Luisi en la que se refiere al Comité y sus actividades lleva por fecha el 28 de marzo de 1928. En ella señala: "El acto, que resultará grandioso por el entusiasmo que ya se

18 “El Comité Uruguay-México hace conocer su programa de acción”, El País, Montevideo, 10 de mayo 1928, p. 3.

19 La pluma (1927-1931) fue el medio ideológicamente más cercano al Comité pues su director, Alberto Zum Felde, formaba parte del mismo y era un comprometido defensor de la cultura americana, la autonomía intelectual y política del continente. La publicación difundió con frecuencia asuntos vinculados a la cultura mexicana. De este modo, en ella encontramos reproducciones de obras de Orozco y Rivera (núm. 3, noviembre de 1927), comentarios a la obra de los estridentistas ("Poetas de la revolución mexicana”, núm. 5, marzo de 1928) y los Contemporáneos (reseña de "Galería de poetas nuevos de México", nro. 10, febrero de 1929) y un extracto del libro de Tristán Marof México de perfil y de frente que analiza la situación de la universidad luego de la Revolución ("La Universidad Autónoma Mexicana”, núm. 19, septiembre de 1931).

20 El contacto entre Luisa Luisi y Alfonso Reyes fue facilitado por la mediación del también escritor y diplomático Enrique González Martínez (véase la carta de Luisi del 4 de julio de 1927). La uruguaya había tratado a González Martínez durante la residencia de éste en Buenos Aires como Embajador mexicano entre 1922-1924. Abordó su obra en el ensayo "La poesía de Enrique González Martínez", una conferencia dictada en Buenos Aires y que luego fue publicada en Montevideo en 1923 por la editorial Maximino García. 
nota y por las personalidades que en él intervendrán, consistirá en una recepción académica en la flamante Casa del Arte”. ${ }^{21}$ La carta también incluye el programa del acto, quiénes serían los oradores, el tema de sus intervenciones y aspectos vinculados a la difusión. Permite, asimismo, entrever el compromiso con el que Luisi y sus compañeros concibieron el programa de solidaridad con México:

Se trata de un proyecto vasto y bien meditado que ha de obtener un éxito completo para nosotros los organizadores, y para México en especial. Hay ya mucho entusiasmo; cada día recibimos nuevas adhesiones para el Comité, el cual trabaja activamente.

Terminado el ciclo de conferencias trataremos de formar con ellas un volumen para enviar a México. Dígame algo más que a Ud. se le ocurra y que pueda contribuir a nuestra ola de difusión de los valores mexicanos. Sería muy interesante una audición de música mexicana, y si fuera posible una exposición de arte mexicano; pero me parece muy difícil su realización por nuestras solas fuerzas. Si Ud. quisiera prestarnos su colaboración, acaso sería más factible.

Entre las comunicaciones que siguen se encuentra una nota del Comité formalizando la invitación a Reyes, la concreción de los últimos detalles de su visita y el envío de recortes de la prensa montevideana en los que figura el manifiesto del organismo y anuncios de sus actividades. Cuando Reyes llegó a Montevideo, le esperaba nutrida agenda. Tras la bienvenida en el puerto por parte de un pequeño grupo de representantes del Comité, el escritor visitó a Juana de Ibarbourou y la Escuela México; se entrevistó con el presidente de la República, Juan Campisteguy y el ministro de Relaciones Exteriores; concurrió a una recepción en el Círculo de Prensa; brindó una conferencia en la Casa del Arte sobre "Últimas crisis del pensamiento mexicano" 22 y asistió a una función que le dedicó la Casa del Arte representando especialmente para él una obra de autor mexicano.

En lo que respecta al homenaje, éste tuvo un éxito abrumador, según se sigue de los testimonios del propio Reyes, Luisi y la prensa de la época. La oratoria estuvo a cargo de la presidenta del Comité, el poeta Carlos Sabat Ercasty, ${ }^{23}$ el Ministro de Instrucción, Enrique Rodríguez Fabregat, y el pro-

21 Más conocido como Teatro Albéniz, durante el año 1928 funcionó bajo el nombre de Casa del Arte y fue un dinámico centro de actividades culturales en Montevideo.

22 Reyes, Diario II, p.55.

23 Reyes y Sabat Ercasty mantenían contacto epistolar desde antes de este encuentro. En el Archivo Literario de la Biblioteca Nacional de Uruguay figura una carta de Reyes (fechada en Madrid en 1923) al uruguayo en la que agradece haber recibido el Libro del mar (1922); 
pio Reyes. Los discursos fueron "comunicados por radio a toda América" 24 y algunos (el de Luisi y el de Reyes) aparecieron en el volumen del mes de julio de la revista La Pluma.

La alocución de Luisi exponía los motivos de la solidaridad uruguaya con México y constituye una clara muestra del americanismo exaltado que inspiraba la labor del Comité: "México se halla hoy, señores, por la senda más dura y más áspera, en caminos de ascensión hacia su meta. Su carne se desgarra en zarzas y en espinas, y sangra por las mil heridas de su pueblo. México dolorido, México crucificado en la lucha intestina de sus hijos, es sin embargo, el México de la democracia que se forja arrancando el cuerpo ensangrentado, con la carne acaso gangrenada, los trozos de la carne vigorosa". ${ }^{25}$

Por otra parte, la autora justificaba la elección de Reyes como figura representativa de México por ser él "uno de los hijos más preclaros del noble país mexicano", a quien se le reconocía "su obra de acercamiento espiritual entre ambas naciones": ${ }^{26}$

Aquí estamos reunidos, señores, para tributar nuestro homenaje a quien por sus preclaras condiciones de talento natural, por la intensa cultura de su espíritu, por la amplitud de su noble visión de intelecto, por el don sagrado y fatal de la poesía, por su abierto corazón de hombre y por el oro y el diamante de su carácter, hemos elegido para representar a México en esta hora, no en su función de Embajador de su Gobierno, sino en este otro de Embajador de la cultura y de las letras mexicanas. ${ }^{27}$

Asimismo, el discurso de la poeta uruguaya revelaba lo efectiva que era la labor de la diplomacia de las letras impulsada por México, que ya por entonces contaba con una destacada genealogía de "heraldos de la nación”.

Hemos aprendido a conocer y amar a la nación hermana, a través de sus más grandes literatos, convertidos por la sabia diplomacia mexicana, en los más puros heraldos de su cultura nacional. Así amamos y lloramos con hondo dolor de poetas y de hermanos al dulce Amado Nervo, que en su cristiana generosidad, nos lo dio todo, su corazón de Asís, y el mismo soplo vital de su exis-

tal vez haya sido ésta la razón por la cual Sábat Ercasty fue designado por el Comité para presentar una valoración del intelectual mexicano.

24 Reyes, Diario II, p. 54.

25 Luisi, "Discurso de homenaje a Alfonso Reyes", p. 20

26 Ibíd., p.19

27 Ibíd., p.20 
tencia. Así aprendimos a conocer y a amar al noble poeta González Martínez, de tan alta espiritualidad en su poesía como noble dignidad en su arte; amigo grande a quien recuerdo hoy emocionada en esta fiesta que el Uruguay dedica a México. Y así también Alfonso Reyes, investido por un Gobierno transitorio de una transitoria Representación Diplomática, inviste, hoy y siempre para nosotros, la representación ilimitada de la cultura de su pueblo. ${ }^{28}$

A su turno, Reyes expresó agradecimiento por las muestras de afecto y de solidaridad con su país. Dedicó un comentario al legado social de la Revolución, destacando el esfuerzo de México para que toda la masa social "disfrute igualmente de las escasas piedades que nos brinda la tierra. Queremos, a costa de nuestro dolor, conquistar un poco de felicidad para todos". ${ }^{29}$ Por otra parte, la prédica de amistad entre las naciones que advirtió en las bases del Comité Uruguay-México inspiró al intelectual regiomontano un panegírico en el que asoman aspectos interesantes de la imagología de lo uruguayo: "Regocijaos, oh patria diminuta y grande; propicia a las inquietudes generosas, consciente de que la vida es una constante progresión penetrada del sentimiento de lo mejorable y lo perfectible; regocijaos, oh ensayo de felicidades cívicas propuesto a los pueblos como índice de entusiasmo y aliento, oh ciudad bajo las alas de Ariel, porque sabéis hacer al mundo señales a cuya luz se reconozcan los hombres de buena voluntad". ${ }^{30}$ En este pasaje se evidencia la fuerza del relato batllista, que difundió la imagen de Uruguay como una república estable, progresista y respetuosa de las leyes. También se advierte en el discurso de Reyes la impronta de Rodó, cuya lectura constituyó su lazo más decisivo con la cultura uruguaya. El joven Reyes, junto a los intelectuales que integrarían el Ateneo mexicano (Gómez Robelo, Antonio Caso, Isidro Fabela y Vasconcelos, entre otros), vio en el autor de Ariel una suerte de maestro. El pensamiento del uruguayo representó para su generación la salida del positivismo y una gran influencia en la forja de su espíritu americanista. ${ }^{31}$

Si bien la participación de Reyes en las actividades del Comité UruguayMéxico se redujo a este homenaje, la ingente fama del autor dotó de prestigio y visibilidad a los eventos inaugurales del grupo. No medió demasiado tiempo entre su visita a Montevideo y la organización, por parte del Comité,

28 Ibíd.

29 Reyes, “Ante el comité Uruguay-México”, p. 21.

30 Ibíd., p. 22.

31 No podemos dejar de recordar que la primera edición mexicana del Ariel (Monterrey, 1908) fue financiada por el general Bernardo Reyes, a instancias de su hijo Alfonso, quien se encargó de la gestión del proyecto editorial. Cfr. Cesana, José Enrique Rodó en México, pp. 115 y 152. 
de un homenaje literario en memoria de Salvador Díaz Mirón (fallecido el 28 de junio de 1928) que contó con una gran afluencia de público y en el que disertaron Emilio Frugoni y Héguy Velazco. El ciclo continuó con una conferencia de Luisi, quien presentó un estudio biográfico sobre Sor Juana Inés de la Cruz; Carlos Sabat Ercasty dedicó una exposición a la obra de Gutiérrez Nájera, y Emilio Frugoni intervino nuevamente con una disertación sobre los logros y dificultades de la Revolución mexicana. ${ }^{32}$

Entre los efectos duraderos del acto consagratorio de Reyes en Montevideo se cuenta el incremento de sus corresponsales uruguayos a partir de 1928. El tendido de esta nueva red epistolar incluyó —aparte de Luisi- a Juana de Ibarbourou, Enrique Amorim, Alberto Zum Felde, Clara Silva, Emilio Oribe, Giselda Zani y Carlos Reyles. Ellos recibieron Monterrey, el correo literario de Reyes, así como las obras que éste fue editando. A su vez, el escritor mexicano recibió las publicaciones de los uruguayos y eventualmente colaboró con su difusión, como se comprueba en el primer número de la revista $S u r,{ }^{33}$ en el que el autor dedicó reseñas a libros de Juana de Ibarbourou y Ángel Aller, o más adelante, en 1939, cuando escribió un breve ensayo sobre la filosofía de Carlos Vaz Ferreira, motivado por la re-edición de las conferencias de éste por la editorial Losada. ${ }^{34}$

\section{AMISTAD LITERARIA Y PROPAGANDA CULTURAL}

Algunas semanas después del homenaje, Reyes manifestó de esta suerte su agradecimiento a Luisi y al Comité:

Dejando aparte los muchos motivos de admiración y afecto que me unen a Usted, esta vez sólo me dirijo a la persona que representa al Comité UruguayMéxico, para rogarle de una manera muy especial que haga presentes a todos y cada uno de sus miembros y reciba para sí, las expresiones de gratitud que, verdaderamente, quisiera demostrarse en obras mejor que en palabras. Uste-

32 Se trató, en realidad, de una conferencia que se prolongó en dos jornadas debido al vasto conocimiento que mostró Frugoni y al enorme interés del público por el tema. Las conferencias fueron recogidas en un impreso titulado La lección de Méjico (1928). El líder del Partido Socialista uruguayo vio entre los logros de la Revolución mexicana la resolución del problema del latifundio y el fin de la explotación de los trabajadores. Abogado y profesor de la Facultad de Derecho, el intelectual se detuvo especialmente en la Constitución mexicana de 1917, a la que presentó como una "Constitución de avanzada” para América Latina. Cabe apuntar una muestra de la red establecida entre México y Uruguay a través de Reyes: una reseña del impreso mencionado figura en la sección "Libros de México y sobre México recibidos” en el número 9 (febrero de 1929) de la revista Contemporáneos.

33 Cfr. Reyes, “Compás poético”, en Sur, n 1, Buenos Aires, 1931, pp. 64-73.

34 Cfr. Reyes, "La filosofía social de Carlos Vaz Ferreira". 
des, desde los primeros momentos, han salido gallardamente a la defensa de nuestros comunes ideales americanos, y —ante las conjuraciones de mala voluntad e incomprensión — no han dudado en ponerse de parte de México, cuyo conocimiento difunden con tanto amor y tanta ciencia. ${ }^{35}$

El escritor vio en las actividades del Comité un instrumento para amplificar los efectos de la diplomacia cultural del México posrevolucionario en el Río de la Plata. En contraste con el campo intelectual argentino que, en su cosmopolitismo europeísta, manifestó escaso interés por la cultura mexicana que tanto pretendía promover el diplomático (y eligió, según Myers, al Reyes del humanismo liberal ${ }^{36}$, la recepción uruguaya cumplió una función compensatoria, dado el fervor y la solidaridad de los intelectuales orientales con la coyuntura mexicana. Por otra parte, también habría que considerar, para ponderar cabalmente su relación con el Comité, un hecho previo a su instalación en Buenos Aires como Embajador. A principios de 1926, Genaro Estrada, jefe del servicio exterior mexicano durante Calles, comunicó a Reyes el descontento del presidente en relación a cómo él y su par, Enrique González Martínez, desarrollaban su labor diplomática. "Se les reprocha dedicar demasiado tiempo a la literatura en vez de ocuparse de sus responsabilidades oficiales”. Este episodio preocupó al escritor-diplomático y provocó que a partir de entonces se esforzase más que nunca en "la organización de actos de propaganda, en satisfacer los deseos de la Secretaría”. ${ }^{37}$

Para ello no sólo se valió de las estrategias de la diplomacia, sino también de aquéllas vinculadas a la amistad literaria o sociabilidad intelectual. A su juicio, la representación de México no se reducía a la órbita de las tareas administrativas; era una labor de propaganda cultural y espiritual que debía nutrirse "sobre todo del trato y de la presencia, del influjo y el atractivo personal". ${ }^{38}$ Ésta fue precisamente la estrategia que el escritor siguió en la relación con Luisa Luisi, puesto que no sólo resultó en una especie de padrino de lujo para la empresa americanista de la autora -quien continuó escribiéndole tras el homenaje para solicitarle orientación en relación a las actividades del Comité, relatarle el desarrollo de las mismas o enviarle las notas que la prensa les dedicaba- sino que se preocupó por mantener la comunicación y por atender de forma solícita un buen número de pedidos y de inquietudes manifestadas por ella, tanto en relación a la cultura mexicana

35 Reyes, Carta del 5 de julio de 1928, Archivo Particular de Alfonso Reyes. Capilla Alfonsina-INBA-Secretaría de Cultura, Expediente $n^{\circ} 1498$, Luisa Luisi.

36 Myers, "El intelectual diplomático. Alfonso Reyes, sustantivo”, p. 83.

37 Zaïtzeff, "Introducción”, en Con leal franqueza. Correspondencia entre Alfonso Reyes y Genaro Estrada, p. 13.

38 Reyes en Zaïtzeff, Ibíd., p. 27. 
como al propio quehacer intelectual. "Sus libros son imposibles de encontrar en las librerías de aquí. ¿Sería Ud. tan amable de enviarme alguno, en especial Plano oblicuo, Ifigenia cruel o La visión de Anáhuac?”, escribía Luisi el 10 de abril de 1928. En otra misiva apuntaba: "me llegó su esperada Ifigenia que leí de un solo tirón". ${ }^{39}$

Reyes cumplió también con otros intereses bibliográficos manifestados por la uruguaya, como lo revela la carta a Estrada en la que señala: "Que le envíen todas las publicaciones pedagógicas de Educación a la Srta. Dra. Luisa Luisi, Calle Bicúy (sic.), 1309, $2^{\circ}$ piso, Montevideo". ${ }^{40}$ Hay que apuntar especialmente aquéllos relacionados con Sor Juana Inés de la Cruz y su época. Como se ha señalado, la autora preparó una conferencia sobre la escritora mexicana como parte del ciclo de conferencias del Comité (agosto de 1928). Luego del evento le envió el texto a Reyes con la intención de conocer su opinión al respecto y manifestarle su interés en publicar ese trabajo en México. El diplomático le concedió su apoyo gestionando su inclusión en un número de la revista Contemporáneos ${ }^{41}$ y la auxilió con los materiales necesarios para que Luisi completara su estudio, como puede verse en otra carta de Reyes a Genaro Estrada de noviembre de 1928 y que transcribimos íntegra por el interés que reviste.

La poetisa uruguaya Luisa Luisi ha leído recientemente una conferencia sobre Sor Juana de la Cruz, que ella quiere ampliar hasta hacer un verdadero libro. Le he hecho prescindir de la idea de incluir en la obra una antología de Sor Juana, porque eso ya lo ha hecho en México Touissant, y porque Emilio Abreu Gómez va a ser el editor filológico de Sor Juana.

Luisa Luisi necesita que le envíen de México las obras de Pimentel (lo que haya de él o sobre Sor Juana), el México viejo, de González Obregón, y cuanto haya digno de consultarse sobre Sor Juana.

Dado el valor literario de Luisa y su eficaz y operante simpatía por México, creo que la Secretaría puede obsequiar una colección de publicaciones que la animen para acabar su monografía.

Dicha monografía iría manuscrita a México en mi valija, para que allá se publique.

Gracias. Le encarezco la importancia de corresponder con esto a la gran animadora del Comité Uruguay-México. ${ }^{42}$

\footnotetext{
39 Luisi, carta del 10 de mayo de 1928. Archivo particular de Alfonso Reyes. Capilla Alfonsina/INBA.

40 Reyes, Con leal franqueza. Correspondencia entre Alfonso Reyes y Genaro Estrada, p. 180

41 Contemporáneos, nro. 9, México, febrero de 1929.

42 Reyes, Con leal franqueza, p. 163.
} 
El texto es un testimonio del valor de Luisi para la "buena" propaganda de México en el Cono Sur y del peso de las élites intelectuales en la construcción de la imagología cultural en el momento, pues exhibe cómo Reyes empleó todos los recursos materiales que tenía a su disposición e involucró incluso a la Secretaría de Relaciones Exteriores de México para la satisfacción de las solicitudes de Luisi.

Pero la labor diplomática del escritor no terminó allí, pues atendió además las demandas anímicas y espirituales de Luisi. Las cartas fueron para ella un espacio para la amistad y la confidencia, aspecto visible en los numerosos pasajes en los que la uruguaya le comparte al escritor detalles de su vida, en especial los que hacían alusión a su enfermedad, infortunios familiares y otros sinsabores vinculados a la recepción crítica de su obra. Así, escribe: "Soy una fracasada, amigo Reyes, y esta es la única razón de mi silencio" 43 y recibe consuelo de parte de éste:

¡Qué buena carta la suya de diciembre, querido Alfonso! Con qué delicada suavidad sabe Ud. consolar con esa discreción afectuosa que es el signo de la verdadera amistad! (...) Voy a poner en orden mis manuscritos abandonados; a publicar una selección de mis poesías, tal vez un nuevo tomo de ellas que había encerrado en un cajón con ánimo de no verlas más; y acaso también una pieza de teatro casi concluida y un tomo de críticas. ${ }^{44}$

En la amistad epistolar con Luisi, se comprueba lo que ha señalado Adolfo Castañón, la inclinación y disponibilidad de Reyes hacia las amistades femeninas, "más allá de cualquier incidencia erótica”, pues "Reyes tenía, al parecer, una rara capacidad para inspirar confianza entre las damas y para tratarlas con una refinada y fervorosa amistad", ${ }^{45}$ como también se com-

43 Luisi. Carta del 25 de octubre de 1931. Archivo particular de Alfonso Reyes. Capilla Alfonsina/INBA. Un hecho fue decisivo para su desilusión, el juicio lapidario que Zum Felde le dedicó en Proceso intelectual del Uruguay e historia de la literatura (1930): "su poesía es todavía de cuño intelectualista, careciendo su floración gris, de aquella savia vital que viene de las oscuras raíces del ser, y —además, o ante todo- de aquel puro sentido estético, que da valor primario a toda cosa de arte. Las más estimables composiciones de Luisa Luisi, son aquéllas más breves en que se ha olvidado de los problemas filosóficos y los conceptos de cátedra, para emitir voces de su propia intimidad vital” (p. 192). La suerte de la poeta en el sistema literario fue definida por la condena unánime de la crítica del momento a la vertiente cerebral o intelectualista de su obra. El canon epocal establecía que la poesía femenina debía ser sensual y emotiva, como se palpa en las - consagradas - Agustini e Ibarbourou.

44 Luisi, carta 25 de febrero de 1932, Archivo particular de Alfonso Reyes, Capilla Alfonsina/INBA.

45 Castañón, Introducción a Reyes, Diario II, p. XXXII. 
prueba en su correspondencia con Victoria Ocampo, Gabriela Mistral, María Rosa Oliver, Cecilia Meireles o Juana de Ibarbourou.

\section{CAPITAL SIMBÓLICO, LEGITIMACIONES Y CONFLICTOS}

Pero no todo fue entendimiento y amistad literaria entre la uruguaya y el mexicano. Junto a las prácticas de colaboración y de armado de redes, hay que considerar la existencia de otras, más propias del campo intelectual, y que instalan relaciones de conflicto y competencia. ${ }^{46}$

A fines de 1928, las cartas de Luisi comenzaron a asumir notas de desencanto en relación a la continuidad del Comité. La autora se lamentaba de los problemas para reunirse y el despoblamiento de sus filas debido a la radicalización política que algunos entrevieron en las declaraciones del organismo tras el asesinato de Obregón. Lo que Luisi presentó primeramente como un "momento de relâche" 47 en las actividades del grupo era ya la agonía del mismo. Tal vez un tanto agobiada por la frustración de su empresa, la uruguaya escribió: “¿Conocen en México nuestra labor? No me ha llegado el menor eco de allá. ¿'No les importa?”. ${ }^{48}$ Este reclamo de reconocimiento provocó un gran malestar en Reyes, según se desprende de una carta posterior de Luisi en la que relata haber recibido la visita del Ministro de México en Uruguay, Fortunato Vega, quien le hizo saber lo inoportuno de su reclamo: "[Vega] me enteró de una carta de Ud. en la que se refería a mi persona. Le confieso que me sorprendió un poco la interpretación a mi pregunta sobre si en México se interesan por las actividades del Comité (...) No había en aquella pregunta ningún reproche subentendido contra la Legación cuya actividad no estoy en condiciones de juzgar". ${ }^{49} \mathrm{El}$ intento por aclarar el malentendido con Reyes la deja incluso más expuesta: "Para terminar de aclarar este pequeñísimo incidente, aclaro mi pregunta. No he recibido ninguna noticia de periódico o revista que señale la mínima repercusión de esta - por otra parte tan escasa- contribución nuestra al acercamiento de nuestros dos países. Mi pregunta no tenía más alcance que este". Si bien no nos es dado conocer la misiva en la que Reyes pudo haber respondido a esta explicación del incidente, es posible seguir su reacción a la actitud de Luisi en dos textos. Por un lado, al volver a Montevideo, en enero de 1929, el mexicano escribió en su diario: "encontré a Juana de Ibarbourou enferma de

46 Cfr. Bourdieu, Campo de poder, campo intelectual. Itinerario de un concepto.

47 Luisi, Carta del 9 de octubre de 1928. Archivo particular de Alfonso Reyes. Capilla Alfonsina/INBA.

48 Luisi, Carta del 23 de noviembre de 1928. Ibíd.

49 Luisi. Carta del 18 de diciembre de 1928. Ibíd. 
la piel y a Luisa Luisi llena de penas de apóstol despechado". ${ }^{50}$ Por otro, en correspondencia reservada a Genaro Estrada, reveló sin tapujos su opinión acerca del servicio de Luisi a México:

Dicho Comité, que comenzó un excelente ciclo de conferencias sobre México y ha hecho mucho por la buena propaganda de nuestro país, lleva algunos meses de agonía. Luisa Luisi es mujer de temperamento político. Su empresa, independientemente de estar inspirada en una sincera simpatía por el nuevo espíritu mexicano, tenía mucho de campaña de política literaria y universitaria. Acaso ella soñó ser llamada desde México y llegar allá en triunfo como otra Gabriela Mistral. El Comité ha sufrido las vicisitudes de la situación personal de ella dentro de la política escolar uruguaya; sus miembros riñieron o desertaron, y prácticamente ya no existe. Con todo, yo no podía prescindir de ella. ${ }^{51}$

Este pasaje, que exhibe el revés de la trama de amistad y diplomacia cultural, cuestiona el envoltorio espiritual y altruista del americanismo de los dos personajes. A la vista está que ambos instrumentalizaron su relación procurando obtener algún tipo de beneficio para la proyección de su carrera. Si el acercamiento de Luisi a la causa de México perseguía el hacerse de un capital simbólico que ayudara a su legitimación en el campo intelectual uruguayo y latinoamericano, ${ }^{52}$ las estrategias diplomáticas de Reyes no estuvieron exentas de dobleces.

Otro episodio relevante para pensar los límites y alcances del vínculo entre Reyes y Luisi y profundizar en la imbricación de la diplomacia cultural y las estrategias del campo intelectual es el de la organización del homenaje a Amado Nervo en Montevideo en 1929. Cabe recordar que éste llegó a Uruguay en mayo de 1919 como Ministro Plenipotenciario de México y falleció allí al poco tiempo de su arribo. La muerte del autor de La amada inmóvil suscitó la muestra más grande de duelo y solidaridad continental que haya registrado la historia de Latinoamérica y, por otra parte, un verdadero hito en la proyección del México posrevolucionario en el exterior. Entre los

Reyes, Diario II, p. 89.

51 Reyes, Con leal franqueza, p. 206.

52 De hecho, resulta llamativo que tras este capítulo de intensa prédica americanista, Luisi mostrara un acercamiento al panamericanismo. En 1930 publicó La literatura del Uruguay en el año de su centenario en el Boletín de la Unión Panamericana. En otro orden de cosas, la comparación de la autora con Mistral, esa "doble" chilena, también poeta y educadora, y con una fuerte presencia en redes americanistas y feministas, resulta sumamente significativa. Que Reyes oponga a Mistral como medida de proyección o ambición constituye un gesto potente e incisivo, máxime si se tiene en cuenta la amistad que mantenían la uruguaya y la chilena. 
uruguayos, las muestras de dolor y los honores tributados al poeta y diplomático cobraron dimensiones insólitas; ${ }^{53}$ de hecho, a finales de los años veinte, la figura más importante de la cultura mexicana en el imaginario uruguayo era aún Amado Nervo.

Esa presencia de "el gran muerto", como lo llamaba Reyes, y la enorme admiración que éste le prodigaba hizo que el 7 de mayo de 1929, le hiciera a Juana de Ibarbourou "un encargo de piedad": la organización de un homenaje a Nervo, a diez años de su deceso en Montevideo. "Amiga mía: Ud. que posee la voz más pura, convoque a algunos poetas escogidos: hagan un acto breve y claro en memoria de aquel justo" ${ }^{54}$ Ante este pedido, la poeta se comprometió a dar vida a dos eventos:

Una conferencia en el Centro Gallego, que es hoy por hoy uno de los salones más prestigiosos y lujosos de acá y "una hora de fervor en memoria de Nervo" en la Universidad. Además, pienso en un álbum que se pondría en el atrio de la Universidad para ser firmado por el pueblo y enviarlo luego a México, o un pergamino con un mensaje a Vd., firmado por los intelectuales uruguayos. ${ }^{55}$

Reyes escribió también a Luisi para que emprendiera gestiones en este sentido ante la revista Alfar, de la que era colaboradora. ${ }^{56}$ La presidenta del Comité Uruguay-México respondió de esta suerte: “¡Cuánto siento que no me haya escrito Ud. antes para recordarme el aniversario de la muerte de Amado Nervo! Era realmente la oportunidad para realizar mi gran homenaje a su memoria, cuya iniciativa correspondía naturalmente por derecho propio al “Comité Uruguay-México". Este no se reúne desde hace meses, pero no quiere decir que hayamos abandonado la labor”. ${ }^{57}$ Más tarde, al enterarse por la prensa de que sería Juana de Ibarbourou la organizadora de las conmemoraciones, escribió a Reyes "No podría Ud. haber elegido mejor", 58 aunque se lamentó por no haber podido colaborar con los actos dispuestos.

${ }^{53}$ El gobierno decretó duelo nacional y dispuso honores de Estado al escritor, así como el traslado de los restos en un buque de la armada nacional, que fue, a su vez, escoltado por un buque de la Armada Argentina. Se realizaron diversas escalas a lo largo del continente para que le tributaran honores. Puede seguirse una relación de este fenómeno — basada en el Archivo del Ministerio de Relaciones Exteriores de Uruguay- en Gros Espiell, “Amado Nervo en Montevideo".

54 Reyes, Grito de auxilio, p. 37.

55 Ibarbourou, Grito de auxilio, p. 39.

56 Reyes, Diario II, p. 135.

57 Luisi, Carta del 8 de mayo de 1929. Archivo Particular de Alfonso Reyes, Capilla Alfonsina/INBA.

58 Luisi, Carta del 20 de mayo de 1929. Ibíd. 
Los homenajes a Nervo fueron exitosos y constituyeron la última ola del fervor mexicano en Uruguay. Reyes dejó un reconocimiento duradero a la labor de Ibarbourou en la organización de esas conmemoraciones, ${ }^{59}$ un gesto que contrasta con la ausencia de reconocimiento público a Luisi por su labor al frente del Comité. En cierto modo, la idea del homenaje a Nervo en Montevideo representó para el diplomático una oportunidad para legitimar a Ibarbourou sobre Luisi ${ }^{60}$ y a sí mismo como heredero espiritual de Nervo y máximo representante de la cultura mexicana en el Río de la Plata en ese momento. El 5 de junio de 1929, apuntó: "Estoy contento del éxito, en que logré a Juana sin ofender a Luisa" ${ }^{61}$ y en la ya citada correspondencia reservada a Estrada, dejó un relato de cómo se condujo en la triangulación con las dos escritoras:

Al acercarse el décimo aniversario del fallecimiento de Amado Nervo, juzgué conveniente procurar que los países del Plata hicieran algo en su recuerdo. Como conozco la calidez de los entusiasmos uruguayos y allá murió Nervo, me pareció que -aparte de lo que yo, personalmente y con mi pluma, hiciera en Buenos Aires- habría que intentar el acto público más bien en Montevideo. (...) Pero la parte delicada de la tarea era el homenaje público que yo deseaba en Montevideo. En aquella ciudad, como Ud. sabe, Luisa Luisi organizó hace tiempo cierto Comité Uruguay-México que trabajó muy bien a los comienzos, $\mathrm{y}$ al que yo mismo debo los brillantes agasajos y cariñosas fiestas con que fui recibido allá por mayo del año pasado. (...) Por otra parte, me parecía más digno de la memoria de Nervo que fuera Juana de Ibarbourou la que organizara tal homenaje, y entre ambas mujeres se ha producido hace mucho no sé qué disidencia, que por lo demás saben cubrir y disimular con perfecta discreción. Opté por el camino directo y escribí a ambas; me encontré con que Luisa estaba sin elementos, y ella misma reconocía que la iniciativa le tocaba a Juana. ${ }^{62}$

59 Véase: Reyes, “Carta a Juana de Ibarbourou” y “A vuelta de correo”.

60 En su diario, Reyes tiende a comparar a las dos escritoras uruguayas, estableciendo una clara predilección por Juana. El 21 de diciembre de 1928, el autor apuntaba: "Hoy se inicia el día contestando dos cartas de las poetisas uruguayas: el noble dolor de Juana de Ibarbourou, y los pequeños resentimientos de la molesta Luisa Luisi” (Reyes, Diario II, p. 82). En cierto modo, la relación de Reyes con Luisi se vio afectada por su amistad con Juana de Ibarbourou. El autor suele representar a una Ibarbourou elevada, pura en sus sentimientos y motivaciones, y a una Luisi, política, mezquina y proclive a la queja. Paradójicamente, durante la década del treinta, Luisi estaría ideológicamente más cerca de Reyes que Juana, debido a su apoyo a la causa de la República y su condena al franquismo. La "esposa de América”, en cambio, se encerró en una postura católica y reaccionaria que, de hecho, comenzaría a signar su opacamiento en un campo intelectual cada vez más politizado.

61 Reyes, Diario II, p. 140.

62 Reyes, Con leal franqueza, pp. 205-207. 
Luisi atendió al pedido de Reyes y publicó una nota titulada "Un recuerdo de la muerte de Amado Nervo", la que incluía -significativamente- una dedicatoria a Alfonso Reyes. Si la escritora esperó de Reyes una suerte de dádiva que mejorara su posicionamiento en el campo literario uruguayo, a partir de esta instancia debió de abandonar sus esperanzas, ya que, en el encargo del homenaje a Ibarbourou, el escritor-diplomático realizó una clara transferencia de prestigio a esta última, al tiempo que un acto de exclusión propio de las relaciones de poder y competencia que conforman el campo intelectual.

Por otra parte, este episodio puede leerse como un adelanto de la apoteosis de Juana de Ibarbourou, que tendría lugar pocos meses después, en agosto de ese mismo año, cuando en un acto multitudinario en el Palacio Legislativo fuera desposada con América, con la bendición tutelar de dos escritores varones: Juan Zorrilla de San Martín y del propio Reyes. En esta nueva instancia de legitimación, al exponer su loa a la poeta (titulada "Otra Juana de América”) el intelectual mexicano recurrió a una analogía harto significativa para lo que venimos desarrollando, pues ungió a la uruguaya como la heredera de Sor Juana Inés de la Cruz. De esta forma Reyes continuó la operación de legitimación de Ibarbourou iniciada a partir del homenaje a Nervo y al mismo tiempo dio visibilidad a México en uno de los eventos culturales más recordados de la historia de la literatura uruguaya.

\section{Palabras finales}

La relación entre Luisi y Reyes continuó más allá de estos episodios de conflicto, si bien la periodicidad de los intercambios epistolares y los encuentros se vio menguada a partir de 1930, año en que el mexicano se distanció de la vida cultural rioplatense a raíz de sus funciones como embajador de México en Brasil.

En la correspondencia de los años que siguieron, Luisi envió a Reyes comentarios sobre Monterrey, agradecimientos por el envío de obras y ciertas quejas por no poder ver al escritor cuando éste hacía escala en Montevideo, camino a Buenos Aires o Río de Janeiro. Todo indica que ya no volvieron a encontrarse, si bien Reyes siguió visitando la capital uruguaya durante la década del treinta. ${ }^{63}$

Podría afirmarse que el intercambio más intenso entre ambos estuvo ligado a la existencia del Comité México-Uruguay y su ola de difusión de

63 En el diario del autor, sí se registran encuentros con Ibarbourou, Díez Canedo, Julio J. Casal y Emma Barón de Supervielle, pero no con Luisi. 
los valores del México posrevolucionario, para el que la presencia de Reyes en el Río de la Plata funcionó como un gran estímulo. Pero también debe reconocérsele a Luisi su papel como mediadora, pues su trabajo representó una enorme contribución al fortalecimiento de las redes entre las dos naciones y la circulación y el conocimiento de la cultura mexicana en Uruguay, esto es, la "propaganda espiritual" de México que tanto preocupaba al escritor regiomontano.

Por último, la relación de Luisi y Reyes permite profundizar en los vericuetos del americanismo y en la compleja trama que hilvanaba los intereses de la diplomacia cultural con las dinámicas propias del campo intelectual. Según se ha propuesto en este trabajo, el prestigio de una carrera literaria y de la representación del México posrevolucionario otorgaron a Reyes una autoridad que supo proyectar sobre un sistema cultural extranjero como el uruguayo. Este aspecto más político del animador de redes latinoamericanas que fue Reyes tal vez sirva para completar un capítulo más de los literatos en el servicio exterior de México.

\section{REFERENCIAS}

\section{ARCHIVOS}

Archivo Particular de Alfonso Reyes. Capilla Alfonsina/INBA/Secretaría de Cultura, México, Expediente $n^{\circ} 1498$, Luisa Luisi.

Archivo Literario de la Biblioteca Nacional de Uruguay.

\section{BIBLIOGRAFÍA}

Álvarez, Myriam, Introducción, en Luisi, Luisa. Antología: verso y prosa, Salta, Editorial.

Biblioteca de Textos universitarios, 1998, pp. 9-36.

Benítez, Ángel, Luisa Luisi. El ensueño dolorido, Montevideo, Barreiro y Ramos, 1981.

Bourdieu, Pierre, Campo de poder, campo intelectual. Itinerario de un concepto, Buenos Aires, Montressor, 2002.

Caetano, Gerardo y José Pedro Rilla, El joven Quijano, 1900-1933: izquierda nacional y conciencia crítica, Montevideo, Ediciones de la Banda Oriental, 1986.

Caetano, Gerardo (coord.), Los uruguayos del Centenario. Nación, ciudadanía, religión y educación (1910-1930), Montevideo, Santillana, 2000.

_ La República Batllista, Montevideo, Ediciones de la Banda Oriental, 2011.

Castañón, Adolfo, Introducción, en Reyes, Alfonso. Diario II. París, 19 de marzo de 1927-Buenos Aires, 4 de abril de 1930, edición crítica, introducción, notas, 
fichas bibliográficas, cronología e índice de Adolfo Castañón, México, Academia Mexicana de la Lengua, El Colegio de México, El Colegio Nacional, FCE, INBA, Capilla Alfonsina, UAM, UANL, UNAM, 2010.

Cesana, Raffaele, “José Enrique Rodó en México”, tesis doctoral, Universidad Nacional Autónoma de México, 2016, disponible en: <http://132.248.9.195/ptd2016/octubre/508450459/Index.html>, fecha de consulta: 10 de septiembre de 2018.

“El Comité Uruguay-México hace conocer su programa de acción”, El País, Montevideo, 10 de mayo de 1928, p. 3.

Frugoni, Emilio, La lección de Méjico, Montevideo, Imprenta Augusta, 1928.

Garciadiego, Javier, “Alfonso Reyes en la Argentina: desencuentros diplomáticos y amistades literarias”, en Autores, editoriales, instituciones y libros. Estudios de historia intelectual, México, El Colegio de México, 2015, pp. 229-254.

Granados, Aimer, “Alfonso Reyes en Sur América: diplomacia y campo intelectual en América Latina, 1927-1939”, Historia y Espacio, núm. 38, Cali, 2012, pp.11-28.

Gros Espiell, Héctor, “Amado Nervo en Montevideo”, Revista de la Universidad de México, núm. 471, Ciudad de México, abril de1990, pp. 42-47.

Krauze, Enrique, Plutarco Elías Calles. Reformar desde el origen, México, FCE, 1992.

López, Sara, El legado de las hermanas Luisi, cien años después, Montevideo, Facultad de Humanidades y Ciencias de la Educación/ Universidad de la República, 2013.

Luisi, Luisa, “Discurso de homenaje a Alfonso Reyes”, La pluma, núm 7, Montevideo, julio de 1928, pp. 19-21.

, "Un recuerdo de la muerte de Amado Nervo", en Alfar, núm. 63, Montevideo, mayo de 1929, pp. 16-17.

, La literatura del Uruguay en el año de su centenario (1930), monográfico del Boletín de la Unión Panamericana, Washington, julio de 1930.

Murciano Mainez, Carlos María, "Hacia una revisión de la poesía posmodernista femenina en el Uruguay (en su primera época)”, tesis doctoral, Universidad Complutense de Madrid, 2002, disponible en $<$ https://eprints.ucm.es/3663/1/T21299.pdf>, fecha de consulta: 28 de agosto de 2018.

Myers, Jorge, “El intelectual diplomático. Alfonso Reyes, sustantivo”, en Altamirano, Carlos (dir.), Historia de los intelectuales en América Latina. II. Los avatares de la "ciudad letrada" en el siglo XX, Buenos Aires, Katz, 2010, pp. 82-97.

Rama, Carlos, “La Revolución mexicana en Uruguay”, Historia Mexicana, núm. 2, Ciudad de México, 1957, pp. 161-186.

Reyes, Alfonso, “Ante el comité Uruguay-México”, La pluma, núm. 7, Montevideo, julio de 1928, pp. 21-23. 
——, “Compás poético”, Sur, núm. 1, Buenos Aires, 1931, pp. 64-73.

, “Carta a Juana de Ibarbourou”, en Tránsito de Amado Nervo. Obras Completas. VIII, México, Fondo de Cultura Económica, 1958, pp. 31-38.

__ " “A vuelta de correo”, en Obras Completas VIII, México, FCE, 1958, pp. 427449.

— tas. IX, México, FCE, 1958, pp. 174-177.

Reyes, Alfonso y Genaro Estrada, Con leal franqueza. Correspondencia entre Alfonso Reyes y Genaro Estrada, tomo II, compilación y notas de Serge I. Zaïtzeff. México, El Colegio Nacional, 1993.

Reyes, Alfonso y Juana de Ibarbourou, Grito de auxilio. Correspondencia, Serge I. Zaïtzeff (comp.), México, El Colegio Nacional, 2001.

Reyes, Alfonso, Diario II. París, 19 de marzo de 1927-Buenos Aires, 4 de abril de 1930, Adolfo Castañón (ed.), México, Academia Mexicana de la Lengua, El Colegio de México, El Colegio Nacional, FCE, INBA, Capilla Alfonsina, UAM, UANL, UNAM, 2010.

Santacreu, María José. “Luisa Luisi: sentada y muda al borde de la vida”, en Pereira, Cielo (coord.), Mujeres uruguayas II. El lado femenino de nuestra historia, Montevideo, Santillana, 2001, pp. 111-138.

Vitale, Ida, Los poetas del Veinte, Capítulo Oriental. Historia de la Literatura Uruguaya núm. 21, Buenos Aires, Centro Editor de América Latina, 1971.

Yankelevich, Pablo, Miradas australes: propaganda, cabildeo y proyección de la revolución mexicana en el Río de la Plata, 1910-1930, México, Instituto Nacional de Estudios Históricos de la Revolución Mexicana, 1997.

Zaïtzeff, Serge, "Introducción”, en Con leal franqueza. Correspondencia entre Alfonso Reyes y Genaro Estrada, tomo I, compilación y notas de S. Zaïtzeff, México, El Colegio Nacional, 1993.

Zum Felde, Alberto, Proceso intelectual del Uruguay y crítica de su literatura, tomo III, Montevideo, Imprenta Nacional Colorada, 1930. 